GenBank - although some of these may not be unique.

The ultimate goal of all these projects is to produce a complete set of full-length human cDNAs, corresponding to all the genes in the human genome. As there are now thought to be only about 30,000 genes, and technologies needed to deal with long or rare cDNAs are improving, this may not take very long - "perhaps only a couple of years", suggests an optimistic Robert Strausberg, head of the NIH project.

With this rapid progress, the need to coordinate these efforts has become more pressing. "It would be nice to have a system whereby different sets of cDNAs were allocated to different groups, so there would not be too much duplication of effort," says Wiemann. Ohara agrees: "A couple of years ago we were the only group in the game, but now we really need to think of an allocation system," he says.

There could be complications in organizing such a system, Strausberg points out, because not all groups make their results freely available to all. The issue is to be discussed in the next few months by the various projects. In the meantime, a joint website is planned to help each project keep up with what the others are doing. http://www.rzpd.de

| http://cgap.nci.nih.gov

http://www.kazusa.or.jp/huge

\title{
Network aims to link species data from global collections
}

\section{Georgina Kenyon, London}

A global programme has been launched to collate information on the world's most important collections of animal and plant species, in a format that is freely accessible to all.

The Global Biodiversity Information Facility (GBIF), which hopes to provide unrestricted access on its website to species information held in existing museum collections, was officially launched in Brussels last week.

The GBIF has received US\$2 million of initial support from its twelve member countries. Subscriptions to the GBIF differ from country to country, depending on their wealth.

It is hoped that the facility will enable scientists in developing countries to have access to the best information about their local biodiversity, often for the first time.

"The complexity of this initiative is vast," says Martin Sharman, a spokesman for the GBIF. About 1.75 million species have been scientifically described in different formats in various collections, but between 10 million and 100 million are thought to exist.

Organizers will decide in July where to place GBIF's secretariat, with Australia, the Netherlands, Denmark and Spain all vying to host it.

"GBIF will assist museums, scientists and educators, and give politicians scientifically factual data," says Carlos Martinez-Riera, a representative of the European Commission and GBIF's chief scientific officer.

Eventually the programme aims to set up a web page for each species, with a standard set of information including characteristics, taxonomy and geographical distribution, Martinez-Riera says.

Several national programmes are currently under way to develop such databases —including Species 2000 in Britain, which is not a full member of the GBIF, but is involved in steering the initiative. At the moment there is a large amount of 'double counting', as scientists have independently discovered and named the same species.

Each member country of the GBIF plans to nominate a scientific institution to head its contribution to the project, which was initiated at the Organisation for Economic Cooperation and Development's Megascience Forum in 1996.

http://www.gbif.org

\section{London museum puts its animals on public display}

\section{David Adam, London}

In a six-month exercise that will provide an important fillip for systemic biology, London's Natural History Museum has started moving its collection of over 20 million zoological samples from storage into a new, purpose-built public archive.

The first specimens being transferred to the $£ 27$ million (US\$39 million) archive are the museum's 'spirit collection' of fish, reptiles and invertebrates stored in alcohol. Many of these were brought back from Charles Darwin's five-year voyage on the Beagle in 1831, and others were collected on Captain James Cook's Endeavour expedition in 1763.

The collection includes rays, komodo dragons and tuatara lizards, the last survivors of a group previously considered to have become extinct at the same time as dinosaurs. Many of these specimens will be going on public display for the first time.

The transfer will provide an opportunity for the museum to compile an electronic database of its specimens, in line with efforts to build up a global computerized catalogue of the specimens currently sitting

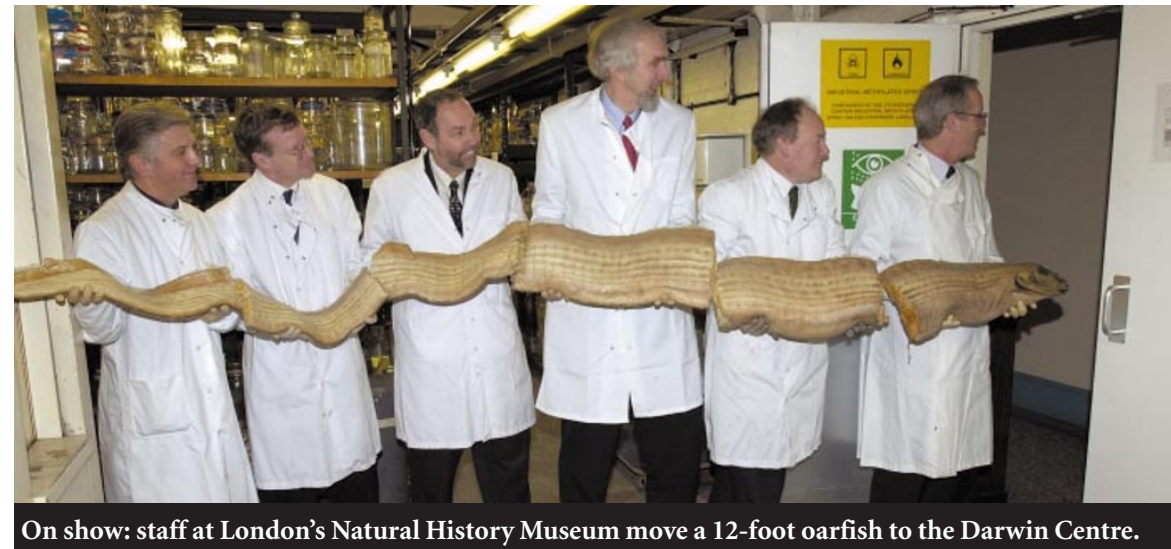

in jars and display cases across the world (see story above).

But a global computerized catalogue is some way off, museum officials say. "There is a drive to get some conformity but it will be a long time before those kinds of standards are agreed," says Paul Henderson, director of science at the museum. "That would be just too labour intensive at the moment because too many institutions have their own systems."
The London museum is making an effort to standardize species names, however, and is trying to make records about where the specimens came from as accurate as possible.

This first phase of the new archive is expected to open in spring 2002. Phase two will then see the 'dry' entomology and botany collections moved to the new facility, which will be known as the Darwin Centre. http://www.nhm.ac.uk/darwincentre/index.html 